\title{
PENGEMBANGAN KETERAMPILAN PIDATO UNTUK MENINGKATKAN SELF-EFFICACY BERBICARA DI MUKA UMUM, PONDOK PESANTREN AL-FALAH, DESA MOJO, KECAMATAN PLOSO KABUPATEN KEDIRI, JAWA TIMUR
}

\author{
Oleh: \\ Najlatun Naqiyah', Muhammad Farid Ilhamudin², Mutimmatul Faidah ${ }^{3}$, Sjafiatul Mardliyah ${ }^{4}$, \\ M. Turhan Yani ${ }^{5}$ \\ Jurusan Bimbingan dan Konseling, Fakultas IImu Pendidikan, Universitas Negeri Surabaya \\ 1 najlatunnaqiyah@unesa.ac.id
}

\begin{abstract}
Abstrak
Pengabdian masyarakat ini bertujuan mengatasi beberapa permasalahan utama yang dialami oleh pondok pesantren, yakni meningkatkan self-efficacy berbicara di muka umum pada santri. Santri kurang bisa memanagemen latihan pidato yang sesuai dengan kondisi sekarang dan berkelanjutan. Sebagian besar santri merasa kurang percaya diri tampil berbicara di muka umum. Sedangkan harapan orang tua kepada anak-anaknya ialah menginginkan mereka menjadi pemimpin dan ahli dakwah ketika kembali ke daerah masing-masing. Permasalahan tersebut yang dialami oleh Pondok Pesantren mitra "Al-Falah", Kecamatan Ploso, Kabupaten Kediri, Jawa Timur. Untuk mencapai tujuan program PKM ini perlu dilakukan managemen latihan pidato bagi santri yang dilakukan setiap minggu. Serta adanya buku ajar keterampilan berbicara di muka umum sebagai pedoman saat latihan pidato. Pelaksanaan kegiatan PKM dilakukan antara bulan Juni hingga November 2019. Berdasarkan data hasil pre-test dan post-test yang diberikan oleh Tim PKM kepada peserta pelatihan pidato kemampuan santri pondok pesantren Al-Falah Ploso Kediri ketika berbicara di depan umum mengalami peningkatan. Hal ini dibuktikan dengan nilai rata-rata saat pre-test sebesar 68,55 sedangkan nilai rata- rata post-test sebesar 73,075 . Serta Dari hasil pelaksanaan PKM nampak santri antusias dalam mengikuti pelatihan pidato dan terdapat beberapa masukan terkait kegiatan selanjutnya.
\end{abstract}

Kata Kunci: Pelatihan pidato, Self-Efficacy, PKM

\begin{abstract}
This community service (pengabdian masyarakat; PKM) aims to overcome some of the main problems inflicted upon students of Islamic boarding schools (pesantren), that is to increase self-efficacy for students to speak in public. Santri has less ability to manage speech in public in accord with current and future conditions. Most students feel less confident to stand in public. Meanwhile parents desired to have their children become leaders and da'wah experts when returning to their respective regions. The very problem inflicted upon pesantren Al-Falah, Ploso, in Kediri Regency, East Java. To achieve the objectives of the PKM, it needs speech trainings for students held every week, and a textbook on public speaking skills as a guide book as they practice the speech. The PKM were carried out between June and November 2019. Based on the results of the pre-test and post-test to the speech training participants, the students' ability of the pesantren Al-Falah Ploso had increased. The result shows the average of the pre-test is at 68.55, while the post-test average is at 73.075. During the PKM, students seemed enthusiastic in participating in the speech training. There are some feedbacks related to the next activity.
\end{abstract}

Keywords: Public speech training, self-efficacy, community services

\section{PENDAHULUAN}

Pondok pesantren Al-Falah berlokasi di jalan raya Mojo 102 Ploso Mojo Kediri. Pondok pesantren didirikan untuk menjadi para pejuang agama Islam yang bisa menyampaikan dakwah bil lisan dan bil haal. Mereka terdiri dari santri yang memiliki tingkat ekonomi dari kelas atas, menengah dan bawah. Pondok Al-Falah memberikan pelayanan pendidikan selama 24 jam. Layanan pendidikan berbentuk asrama putra dan putri yang dikelola oleh Kiai dan Ibunyai. Pondok pesantren memiliki pendidikan 
agama Islam. Kegiatan pendidikan meliputi ibadah sholat lima waktu berjamaa'ah, pelajaran al-Qur'an dan kitab-kitab hukum Islam, akhlak mulia dan keterampilan hidup yang langsung dikendalikan oleh system pamong. System pamong adalah kerjasama antara orang tua dan pengasuh di pondok pesantren.

Setiap hari pengasuh mengontrol anak-anak sebagaimana orang tua. Mulai dari kegiatan solat tahajud jam 03.00 , solat subuh, solat duha berjamaah. Setiap pagi mereka berangkat sekolah dengan melakukan ijin ke pengasuh dengan mencium tangan sebagaimana anak ke orang tua. Pulang sekolah setelah dhuhur. Para santri istirahat dan melakukan solat asar berjama'ah, mengikuti sekolah diniyah dengan kurikulum kitab kuning. Pada malam hari ada kegiatan solat magrib berjama'ah, dan mengaji al-Qur'an sampai tiba waktu isya' kemudian solat berjamaah dilanjutkan dengan belajar bersama. Kegiatan pidato adalah kegiatan ekstrakurikuler yang dilakukan setiap hari ahad, dimana anakanak santri libur sekolah.

Berdasarkan kegiatan diatas pondok pesantren menekankan pada aspek keagamaan sosial. Aspek ini menyiapkan para santri untuk bisa berkerja dan beramal sholeh. Salah satu peran santri adalah menjaga tradisi agama dan dakwah islam. Santri perlu dibekali keterampilan dakwah untuk menyampaikan pesan agama. Pesan agama dengan melalui metode ceramah dinilai lebih efektif.

Berbicara di depan umum dengan menyampaikan pesan-pesan agama biasa di sebut dengan pidato. Keterampilan pidato adalah keterampilan berbicara di depan umum (public speaking). Keterampilan pidato menurut Ronny H Mustamu (2012) adalah memadukan 4 unsur yaitu science, art, soul and skill. Perpaduan antara ilmu pengetahuan, keterampilan, seni dan jiwa adalah kemampuan personal dan interpersoanal dalam bakat individu. Sedangkan dalam Islam model dakwah pertama yang dilakukan oleh Nabi Muhammad SAW ialah ceramah. Menurut Rakhmawati (2014) Dakwah adalah soal mempengaruhi audience. Cara berdakwah memerlukan strategi dalam pelaksanaanya untuk dapat mempengaruhi audience. Salah satu cara untuk mempengaruhi audience ialah dengan latihan secara langsung. Pengalaman langsung bagi para santri untuk belajar berbicara di depan umum akan meningkatkan rasa keyakinan untuk berhasil berdakwah. Santri memiliki kewajiban berdakwah pada masyarakat ketika pulang ke daerah masing-masing.

Menurut Santrock (2007) Self-efficacy ialah keyakinan diri terhadap kemampuan yang dimiliki oleh sesorang dengan harapan memperoleh hasil akhir yang maksimal. Self efficacy juga bisa diartikan sebagai sebuah kepercayaan diri sesorang dalam menyelesaikan permasalahan hidup yang dihadapi Robbins (1998). Sedangkan menurut Mangungsong, Murti dan Wijaya (2016) menjelaskan bahwa self efficacy merupakan sudut pandang diri sesorang dalam menilai seberapa bagus dri dapat berfungsi dalam melakukan tindakan yang diharapkan. Jadi self-efficacy untuk meningkatkan rasa keberhasilan pidato adalah kemampuan yang dimiliki oleh siswa dalam berkomunikasi di depan umum dengan tujuan mempengaruhi audience dengan pesan-pesan agama.

Menurut (Linder, Nystrom, Hassmen, Andresson, \& Carlbring, 2015) bagian dari bimbingan belajar agar mampu mempengaruhi orang lain adalah keterampilan berbicara didepan umum atau public speaking. Keterampilan public speaking yang dilatihkan pada siswa sekolah menengah berbasis pondok yaitu dengan menggunakan metode praktik langsung. Public speaking menjadikan siswa belajar menghapalkan materi, menguasai panggung, penampilan gaya, dan intonasi suara sehingga memperoleh rasa keberhasilan yang tinggi (Casteleyn, 2019). Siswa dapat merasakan pengalaman tampil langsung di depan umum serta merasakan sukses dari usaha yang dicapai. Menurut (Dickey Johnson, 2010) Budaya pesantren dapat mepengaruhi lingkungan siswa sekolah menengah untuk memiliki rasa berhasil belajar public speaking. Pengalaman sukses ketika tampil secara langsung atau mendengarkan cerita orang lain yang telah sukses ketika berpidato dapat meningkatkan rasa berhasil pidato pada siswa. Keterampilan public speaking siswa menengah berbasis pondok pesantren dapat menjadi bekal untuk meningkatkan (rasa berhasil) saat pidato di masa mendatang.

Pondok pesantren Al-Falah setiap hari ahad atau ketika santri libur sekolah di adakan kegiatan pidato. Sebagian besar santri merasa kurang percaya diri untuk tampil berbicara dimuka umum, sedangkan harapan orang tua menginginkan anak-anak menjadi penerus pejuang islam dan ahli dakwah ketika kembali ke kampung halamannya. Untuk itu diharapkan dengan memberikan bekal keterampilan dan seni berpidato akan mampu meningkatkan rasa berhasil santri untuk berdakwah. Kedua, dengan keterampilan pidato tersebut, santri memiliki naskah buku pidato dan podium untuk latihan dengan layak.

Kondisi eksistensi pondok pesantren AlFalah sangatlah potensial untuk mengembangkan keterampilan pidato. Dimana anak-anak santri sangatlah cerdas dan berprestasi dalam bidang akademik akan menjadi modal kemampuan untuk menguasai materi pidato jika mereka disediakan sarana berupa buku materi pidato yang jelas. Keterampilan modeling santri meniru dari pelatih yang ahli pidato untuk mencontoh gaya dan seni melakukan komunikasi public. 
Berdasarkan hal yang telah disampaikan di atas, maka dilaksanakan program Pengabdian kepada Masyarakat "PKM-Pengembangan Keterampilan Pidato Untuk Meningkatkan SelfEfficacy Berbicara Di Muka Umum Di Pondok Pesantren Al-Falah Ploso Kediri" yang dilaksanakan pada Tahun 2019. Tujuan PKM ini adalah untuk memberikan rasa berhasil atau self-efficacy bagi santri berbicara di muka umum dengan latihan pidato. Manfaat dari program PKM ini adalah santri mampu memanajemen latihan pidato dari pengorganisasian, perencanaan, pelaksanaan dan evaluasi. Sehingga santri memiliki self-efficacy saat berbicara di depan umum.

\section{METODE}

Metode yang digunakan dalam kegiatan PKM ini menggunakan beberapa metode sebagai berikut:

1. Metode diskusi

Pelatihan pidato kepada santri menggunakan metode diskusi karena santri akan belajar memahami materi yang telah sampaikan dalam pelatihan pitado tersebut.

2. Metode ceramah dan demonstrasi

Dalam pelatihan pidato menggunakan metode ceramah dan demonstrasi karena ketika berpidato nantinya santri akan menyampaikan materi kepada audiens secara lisan serta gerakan tubuh untuk memperjelas materi yang disampaikan.

3. Metode pelatihan dan praktik

Metode pelatihan dan praktek digunakan agar santri bisa secara langsung mengasah kemampuan diri ketika berpidato, mulai dari kepercayaan diri ketika tampil di depan umum, penyampaian materi, serta cara untuk menguasai panggung. Melalui metode ini di harapkan agar santri dapat terus mengasah potensi yang di miliki ketika berbicara di depan umum atau yang biasa di sebut public speaking.

\section{HASIL DAN PEMBAHASAN}

\author{
Pelaksanaan kegiatan PKM "PKM- \\ Pengembangan Keterampilan Pidato Untuk \\ Meningkatkan Self-Efficacy Berbicara Di Muka \\ Umum Di Pondok Pesantren Al-Falah Ploso \\ Kediri”, kerjasama antara Tim PKM Unesa dan \\ Pondok Pesantren Al-Falah Ploso, Kecamatan \\ Mojo, Kabupaten Kediri dilaksanakan bulan Juni
}

hingga November 2019. Seluruh rangkaian kegiatan PKM yang dijalankan adalah sebagai berikut:

1. Rapat koordinasi dengan tim PKM: 11 Juni 2019

2. Survey persiapan mitra: 13 Juni 2019

3. Penyusunan materi pidato I: 17 Juni 2019 3 Juli 2019

4. Rapat koordinasi dengan tim PKM tentang pelaksanaan: 6 Juli 2019

5. Pelatihan pidato I "Pemberian tugas kelompok dengan menggunakan metode diskusi": 8 Juli 2019

6. Pelatihan pidato II "Metode ceramah dan demonstrasi": 17 Juli 2019

7. Pelatihan pidato III "Metode pelatihan dan praktek": 23 Juli 2019

8. Penyusunan laporan: 6 Agustus 2019 -23 Agustus 2019

9. Tim PKM "Pengembangan Keterampilan Pidato Untuk Meningkatkan Self-Efficacy Berbicara Di Muka Umum Di Pondok Pesantren Al-Falah Ploso Kediri" melaksanakan praktik pidato: 14 September 2019

10. Penyusunan buku modul pelatihan pidato: 18 September 2019 - 27 September 2019

11. Publikasi: 4 November 2019

12. Penyusunan laporan: 7 November 2019 - 25 November 2019

Kegiatan rapat koordinasi dengan tim PKM dilakukan pada tanggal 11 Juni 2019. Rapat koordinasi dilakukan untuk revisi proposal serta membahas tentang pelaksanaan PKM yang akan dilakukan. Secara teknis pokok bahasan dalam rapat koordinasi tim PKM ialah membahas tentang persiapan apa yang dibutuhkan serta metode pemberian pelatihan pidato pada santri perempuan dan santri laki-laki Pondok Pesantren Al-Falah Ploso, Kediri.

Kegiatan selanjutnya ialah survey persiapan mitra dilakukan tanggal 13 Juni 2019. Survey ini bertujuan untuk memantau kondisi mitra, berikut kesiapan mitra dalam serangkaian kegiatan PKM. Dari hasil survey diketahui gambaran umum lokasi mitra dan permasalahan yang dialami mitra. Sebagian besar santri merasa kurang percaya diri untuk berbicara dimuka umum, sedangkan harapan orang tua 
anaknya di sekolahkan di pondok pesantren agar ketika kembali ke kampung halaman bisa menjadi pemimpin dan ahli dakwah.

Kegiatan berikutnya yaitu pelatihan pidato I "Pemberian tugas kelompok dengan menggunakan metode diskusi", pada tanggal 8 Juli 2019. Pelatihan pidato II yakni dilakukan dengan "Metode ceramah dan demonstrasi" pada tanggal 17 Juli 2019. Serta pelatihan pidato III "Metode pelatihan dan praktik" pada tanggal 23 Juli 2019. Pada kegiatan ini, peserta yang mengikuti pelatihan sebayak 40 santri yang terdiri dari 20 santri putra dan 20 santri putri. Pemberian pelatihan antara santri putri dan santri putra dilaksanakan di tempat yang berbeda. Dimana santri putri di tempatkan di pondok pesantren Al-Falah putri dengan di bimbing tim PKM putri. Sedangkan santri putra di tempatkan di pondok pesantren Al-Falah putra dengan di bimbing tim PKM putra.

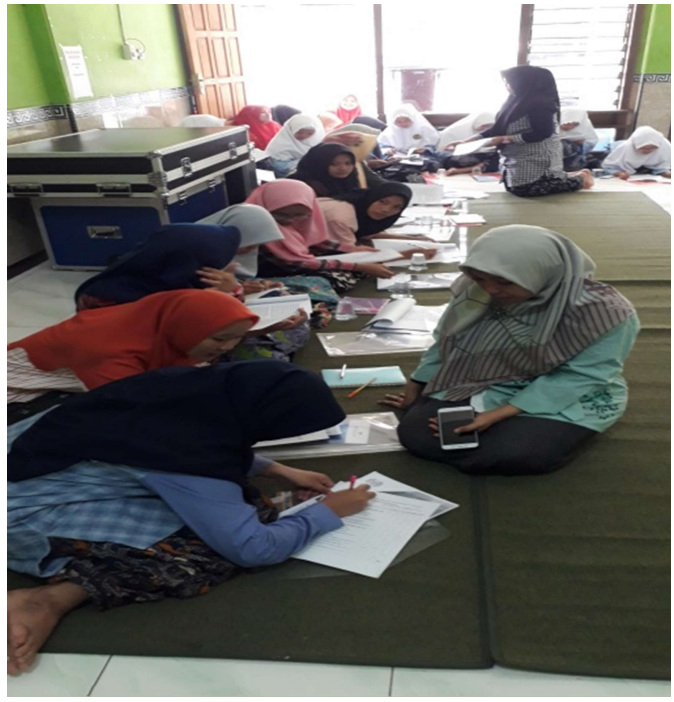

Gambar 1. Pelatihan Pidato I "Pemberian Tugas Kelompok Dengan Menggunakan Metode Diskusi”

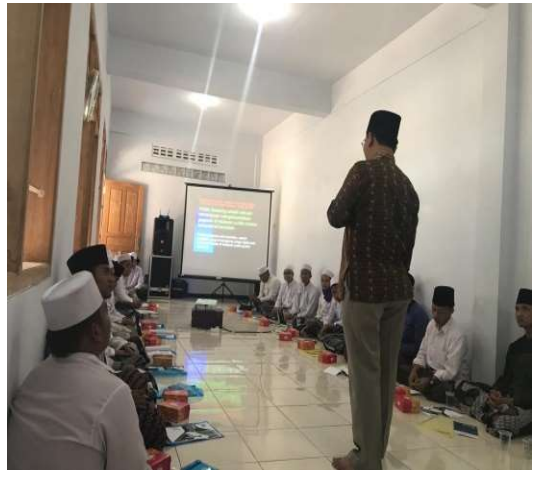

Gambar 2. Pelatihan pidato II yakni dilakukan dengan "Metode ceramah dan demonstrasi"

Selanjutnya yaitu kegiatan tim PKM "Pengembangan Keterampilan Pidato Untuk Meningkatkan Self-Efficacy Berbicara Di Muka Umum Di Pondok Pesantren Al-Falah Ploso Kediri" melaksanakan praktik pidato kepada santri pada tanggal 14 September 2019. Dalam praktik pidato ini dilakukan penilaian untuk mengetahui kemampuan santri saat pidato setelah mendapatkan pelatihan. Semua santri mendapatkan giliran untuk tampil pidato di depan juri dan peserta lainnya sesuai nomer urut. Pada akhir acara di umumkan nilai yang di dapatkan santri saat tampil pidato. Serta tim PKM memberikan angket pre-test dan post-test untuk mengetahui kemampuan pidato santri sebelum dan sesudah pemberian pelatihan. Hasilnya saat pre-test rata-rata nilai santri yaitu 68,55 sedangkan nilai rata-rata post-test yaitu 73 , 07. Sehingga dari hasil pre-test dan posttest diketahui kemampuan santri berbicara di depan umum meningkat.

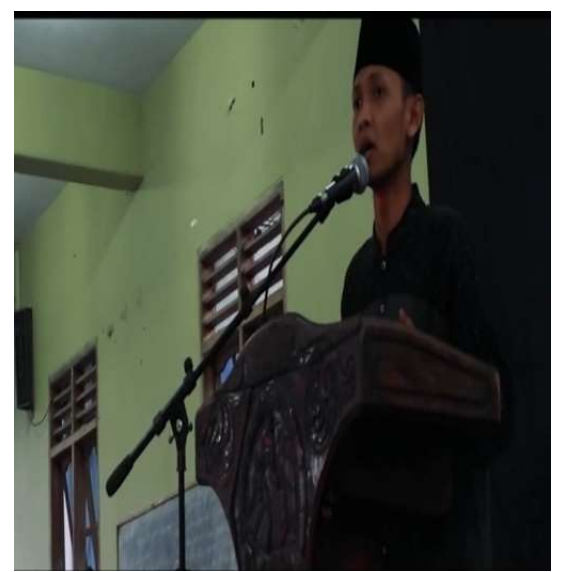

Gambar 3. Penampilan pidato santri putra. 


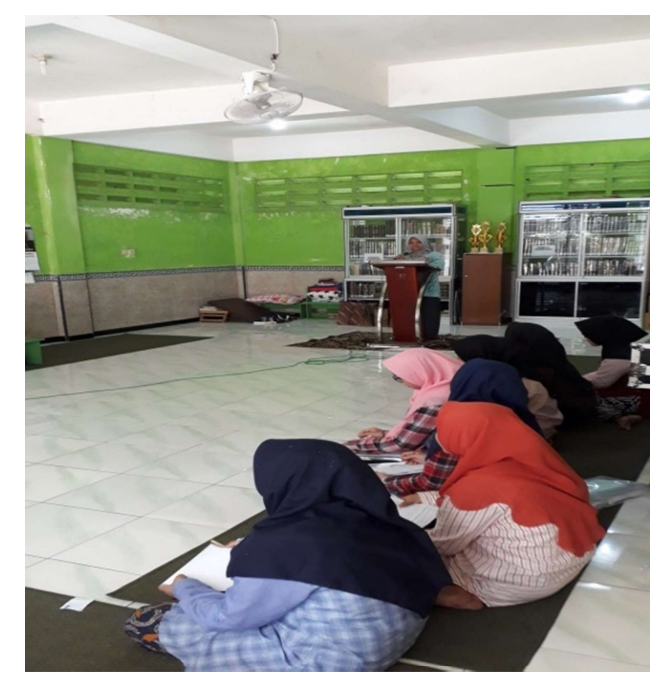

Gambar 3. Penampilan pidato santri putri

Kegiatan kesepuluh yaitu "penyusunan buku modul pelatihan pidato" pada tanggal 18 September 2019 sampai 27 September 2019. Buku modul pidato ini berisi sebagai berikut: faktor penunjang rasa berhasil public speaking, struktur teks, tips berhasil menjadi public speaker, keterampilan public speaking, cara meningkatkan self-efficacy pidato, muqaddimah pidato serta materi-materi tentang pidato. Melalui buku modul pidato ini diharapkan dapat membantu santri atau individu lainnya yang ingin meningkatkan kemampuan berbicara di depan umum.

Kegiatan ke sebelas yaitu "Publikasi" pada tanggal 4 November 2019. Publikasi yang di tampilkan ialah tentang pelaksanaan PKM "Pengembangan Keterampilan Pidato Untuk Meningkatkan Self-Efficacy Berbicara Di Muka Umum Di Pondok Pesantren Al-Falah Ploso Kediri" yang di unggah di alamat : https://fip.unesa.ac.id/blog/tingkatkan-selfefficacy-tim-pkm-fip-unesa-latih-santri-al-falahpublic-speaking/

Dari serangkain kegiatan PKM yang

dilakukan dan berdasarkan angket PKM yang telah diisi oleh peserta PKM, Angket diberikan pada seluruh peserta pelatihan sejumlah 40 peserta. Peserta nampak antusiasme yang sangat besar dari mitra dan peserta PKM yang lain. Peserta sangat antusias mengikuti latihan pidato dan praktik langsung. Peserta hadir mengikuti kegiatan $100 \%$ dan peserta praktik langsung menampilkan pidato 90\%. Berdasarkan hasil isian angket pre-test dan post-test sebagian besar santri pelatihan pidato mengalami peningkatan self-efficacy saat berbicara di depan umum.

\section{SIMPULAN DAN SARAN}

\section{Simpulan}

Berdasarkan hasil kegiatan PKM ini dapat disimpulkan bahwa "PKM-Pengembangan Keterampilan Pidato Untuk Meningkatkan SelfEfficacy Berbicara Di Muka Umum Di Pondok Pesantren Al-Falah Ploso Kediri”, serangkaian kegiatan berjalan lancar dan antusiasme peserta sangat besar. Hampir seluruh peserta mengalami peningkatan self-efficacy saat berbicara di depan umum dengan dibuktikan dengan hasil angket pre-test dan post-test yang diberikan oleh tim PKM. Hasilnya saat pre-test rata-rata nilai peserta yaitu 68,55 sedangkan nilai rata-rata post-test yaitu sebesar 73,07.

\section{Saran}

Saran dari kegiatan pelatihan ini adalah mitra diharapkan dapat mempraktikkan latihan pidato setiap minggu untuk mengoptimalkan potensi yang dimiliki santri sehingga dapat mencapai perkembangan yang optimal.

\section{DAFTAR PUSTAKA}

Mustamu H. R (2012). Menjadi pembicara public handal: Fenomena public speaker antara kebutuhan dan trend. Jurnal Komunikasi Islam. Volume 02 no 02 Desember 2012

Rakhmawati, I. (2014). Keterkaitan Public Speaking dalam Komunikasi Dakwah. AtTabsyir. Jurnal Komunikasi Penyiaran Islam. Volume 2. No 1. Januari-Juni 2014.

Paradewari. S. D. (2017). Investigating Student's Self-Efficacy of Public Speaking. International Journal of Education and Research Vol 5 no 10 Oktober 2017

Bandura A. (2012). Social Foundations of Thought and Action dalam buku Health Psychology Reader.

Bailey, Stephen Bradley, "Efficacy of a Basic Public Speaking Course Delivered via a Virtual Community College" (2012). 
Dissertations.

832.

https://aquila.usm.edu/dissertations/832

Warren, Jami Leigh, (2011). The Relationship Between Service Learning and Public Speaking Self-Efficacy: To ward Engaging Today's Undergraduates. Theses and Dissertations--Communication.

Amy L. Housley Gaffney, Sarah E. Kercsmar, (2016). Students' Affective Learning in a Technologically Mediated Writing and Speaking Course a Situated Learning Perspective. Volume: 30 issue: 3 , page(s): 322-351 